\title{
An Index to Measure Vulnerability of Livestock Owners Livelihood in the Vicinity of National Park
}

\author{
Mukesh Kumar ${ }^{1 *}$, H.R. Meena ${ }^{2}$, Pankaj Seth ${ }^{1}$ and Niva Bara ${ }^{1}$ \\ ${ }^{1}$ Birsa Agricultural University, Ranchi, India \\ ${ }^{2}$ ICAR-National Dairy Research Institute, Karnal, India \\ *Corresponding author
}

\section{A B S T R A C T}

\begin{tabular}{|l|}
\hline Ke y w or d s \\
Index, Livestock owners, \\
Livelihood, Vulnerability \\
\hline Article Info \\
\hline $\begin{array}{l}\text { Accepted: } \\
\text { 17 July } 2018 \\
\text { Available Online: } \\
\text { 10 August } 2018\end{array}$ \\
\hline
\end{tabular}

\section{Keywords}

\section{Introduction}

In developing countries, human-wildlife conflict is more intense where agriculture and livestock farming are important part of people's livelihood and their income (Treves et al., 2006; Eniang et al., 2011 and Kumar et al., 2016). Human wildlife conflict is one of the major threats to conservation, household food security and rural incomes. In India, about 75 percent of rural families are small and marginal farmers. They own 56 percent of large ruminants and 62 percent of small ruminants (World Bank, 1999). Livestock rearing can effectively be used to arrest negative effects of present day challenges to crop farming vis a vis to maintain sustainability of farming for a longer period of time with livelihood security to the farm society. The poor livestock keepers depend heavily on common property resources for their survival (Letha et al., 2016). Livestock in general are more vulnerable to predation than their wild counterparts because they may have lost their natural instinct to effectively fend off the predators (Polisar et al., 2003) because of domestication.

Among livestock types, cattle to be the most vulnerable to predation, probably because cattle were released into the nearby forests more frequently and are mostly not herded (Tshering and Thinly, 2017). Livestock in general were more vulnerable to predation 
when released into the forests without accompanying herders, especially during farming seasons. Proper livestock herding with accompanying livestock herders could minimize predation losses. Vulnerability assessment describes a diverse set of methods used to systematically integrate and examine interactions between humans and their physical and social surroundings. Globally, the issue of vulnerability is now widely highlighted. The role that institutions can play in reducing vulnerability should not be underestimated. The major challenge is to form institutions that contribute towards increasing resilience and adaptive capacity in the face of many other challenges that include climate change, globalisation, social inequalities and epidemics (Wisner et al., 2004).Livestock production, as one among sources of livelihood, has been identified as the backbone for many poor rural communities (Kepe et al., 2004). Many institutional changes in the area such as conservation, wildlife protection, and privatization of market that have resulted in disruption of livelihoods and loss of security among the farming communities (Adger, 1999). Rural people who resides near the national parks, protected area and in the vicinity of forest are vulnerable to the policies associated with the establishment and management of protected areas, as they depend primarily on locally available resources of forest and adjoining area of forest or protected area for their livelihoods and spiritual needs (Maikhuri et al., 2001 and Nepal and Weber, 1995). Subsequent increases in wildlife populations resulted in increased threats to humans, crops and livestock (Wang and Macdonald, 2006 and Wang et al., 2006). Biophysical aspects of crop-raiding focus on crop loss and the landscape factors that render farms vulnerable and ultimately affect the livelihood of the farmers (Rode et al., 2006). The loss of life, crops or livestock to wildlife has significant consequences for people's livelihoods, their food and agricultural security (Barua et al., 2013).

Thus, studies on livelihood vulnerability of livestock owner are the need of the hour. To conduct this type of study, measurement of vulnerability of livelihood wasa tedious process for which limited number of measuring tools are available and literature search revealed that none of the measuring tool is available to measure the livelihood vulnerability of livestock owners hence an attempt has made to develop an index to measure livelihood vulnerability.

\section{Materials and Methods}

This section on research methodology has usually deals with procedural steps required to accomplish the objectives laid down for the investigation. In this section, an attempt has been made to explain the various methods and procedures followed to devise the Livelihood Vulnerability Index (LVI).

\section{Formulation of construct}

It is imperative to operationalize the different concept for ease of measurement. In other words, construct to be formulated in light of the scientific study. A construct is a concept. It has the added meaning, however, of having been deliberately and consciously invented or adopted for a special scientific purpose (Kerlinger, 2012). Different constructs adopted for existing purpose are as under:

Vulnerability: is the degree to which farmers are at risk of crop damage, livestock depredation and human injury combined with individual ability to cope with damage.

Vulnerability is a combination of exposure to risks, sensitivity to shocks and lack of resilience. 
Livelihood: as the means and ways of living to meet the basic minimum necessities of the individual as well as the family. A livelihood comprises the capabilities, assets (material and social resources) and activities required for a means of living. A livelihood is sustainable when people cope with and recover from shocks and crises (e.g. seasonal, environmental and economic) and can maintain or enhance their capability and assets both now and in the future, while not undermining the natural resource base.

\section{Livelihood vulnerability of livestock owners:} The livelihood vulnerability has multidimensional aspects. It includes Human Assets, Natural assets, Social assets, Financial and Physical assets. Therefore, it was important to select dimensions, which were representative indicators of all these sectors of human-life. Vulnerability of livestock owners is as the degree to which livestock owner practiced livestock rearing in the manner, which is economically efficient, socially supportive to the society, environmentally sound in long-term perspective. It is taken as a composite of three indices, i.e. Biophysical vulnerability, Social vulnerability and Institutional vulnerability. Therefore, it took the stock of both, the conflict and synergy between ecological, social and environmental aspects. To measure it, Livelihood vulnerability index (LVI) was constructed as follows:

\section{Development of Livelihood Vulnerability Index (LVI)}

Livelihood vulnerability index requires selection of various dimensions of vulnerability and indicators for assessing the livelihood vulnerability of livestock owners. Composite indicators that integrate various measures into an index can be useful tools for measuring vulnerability (Dale et al., 2001).

\section{Selection of the dimensions of the index}

To develop the index, three dimensions approach included Biophysical, Social and Institutional vulnerability were included.

Biophysical vulnerability: Biophysical vulnerability was operationalized as the exposure of livestock owners, their family and wildlife to natural extreme events and as a consequence to hazard to conflict mitigation skill, awareness regarding conflict mitigation, traditional knowledge, training, injury to human by wild animals, reduction in crop cultivation area, decrease land holding, decline crop yield, herd size reduction, impact on crop and farm diversification, reduction in water availability for crop, availability and scarcity of natural resources and destruction of natural habitat etc. in the vicinity of national park.

Social vulnerability: Social vulnerability was operationally defined as the inability of livestock owners including threats to family, penalties by Government, Social migration due to conflict, Membership of Cooperatives, Socio-political participation due to conflicts in the vicinity of national park.

Institutional vulnerability: Institutional vulnerability refers to the inability of individual livestock owners to cope with change and recovery from wildlife livestock owner's conflicts in terms of physical, financial and institutional level that include the crop loss due to wild animals, loss of livestock due to depredation, impact on major source of family income, household that experience damage to infrastructure, food loss or shortage causes hunger etc.

Determination of scale values of dimensions: It has decided to give specific weights (Scale Values) to each dimension of the LVI based 
on their perceived significance. The Normalized Rank Order Method suggested by Guilford (1954) was used for determining the scale values. The method has a unique advantage that it can be used with any number of variables and does not require a large number of judges.

Judges' rating: As per the Normalized Rank Order Method, three different dimensions of LVI were ranked by the judges according to their perceived significance in determining the status of livelihood vulnerability of livestock owners. Judges are the experts in the field of Forest conservation, Forestry, Wildlife Protection, Social Science, Extension Education, rural developments and farming systems. Questionnaires containing dimensions of LVI were sent by post, through e-mail, Google forms and also handed over personally to the total 55 judges for ranking (1 to 3 ) dimensions according to their relevance in the vulnerability of livelihood of livestock owners. Out of 55 judges 40 judges had returned the same set of indicators after duly recording their judgements in a stipulated span of 2 months. Out of 40 responses, 9 responses were found unsuitable for item analysis and eliminated after careful examination of responses. The remaining 31 responses were considered for the item analysis. The rankings given by all 31 judges were summarised and presented in table 1 .

Calculation of proportions: The proportions were worked out for the ranks assigned by all the judges. The formula is $\mathrm{p}=\frac{(R i-0.5) 100}{n}$, where $\mathrm{R}_{\mathrm{i}}$ stands for the rank value of the dimension " $i$ " in the reverse order as 3 to 1 and " $n$ " indicates the number of dimensions ranked by the judges. The $p$ is the centile value which indicated the area of the dimensions in the normal distribution. The $p$ values were worked out for all the ranks shown in Table 1. Thus, $p$ values for the ranks ranged from lowest 10.00 to 90.00 .
Determining the $C$ Values: The correct rank order (1 to 3 ) is given in the column order $R_{i}$ in Table 1 . The second column $R_{i}$ in Table 1 is the reverse rank order ( 3 to 1 ). The $\mathrm{C}$ values were determined for each rank from the Table M (Guilford, 1954). These values can be traced by putting the finger on the column extreme left of the Table $M$, on the number which indicates the number of stimuli used in the experiment. In the case of this experiment the numbers of dimensions were 3 thus, the number of stimuli to be ranked were 3 .

While moving the finger from this number 3 towards right, stop at the number which indicates the rank $\left(r_{i}, 3\right)$. Above the rank number you can find the respective $C$ value 4 for the rank 7 and this can be entered in the Table 1 under the letter $C$. the $C$ values are from 1 to 9 only. The same procedure may be adapted in finding out the $\mathrm{C}$ values for all the ranks $\left(r_{i}\right)$ from the Table $M$.

Calculation of $\sum\left(f_{j_{i}} C\right)$ value for all the dimensions: This value for every dimension was obtained by multiplying the frequencies found in the columns of the respective dimension by the $C$ values of the rank $\left(r_{i}\right)$, and summing up the products for each dimension and entering the same in the row against $\sum\left(\mathrm{f}_{\mathrm{j}}\right.$ $\left.{ }_{i} \mathrm{C}\right)$. The mean of the total frequencies, that is for the whole data of the matrix was 6.33 $\left.\frac{982}{(155}=6.33\right)$ and the mean of the $C$ values was $6.40\left(\frac{31}{5}=6.20\right)$.

Calculation of scale values of dimensions: Then the $\sum\left(\mathrm{f}_{\mathrm{ji}} \mathrm{C}\right)$ values for each dimension was divided by the total number of judges 31 , which resulted in obtaining the $\mathrm{M}_{\mathrm{c}}=\mathrm{R}_{\mathrm{j}}$. The treatment of data can be stopped at this stage and the $\mathrm{M}_{\mathrm{c}}$ values can be accepted and treated as the scale values. The scale values for biophysical, social and institutional vulnerability were $6.28,6.58$ and 6.27 , respectively. The sum of these values was 31 , 
which was also the total sum of the $\mathrm{C}$ values, indicating the accuracy of calculation. As per the procedure, sum of the scale values and $\mathrm{C}$ values should be same. The mean of the $\mathrm{M}_{\mathrm{c}}$ or $R_{j}$ or $R_{c}$ values was 6.34. The standard deviation and standard error of the $\mathrm{M}_{\mathrm{c}}$ values were 0.15 and 0.03 , respectively (Table 1 ). Selection of the indicators of Livelihood vulnerability: Selection of effective indicators is the key to the overall success of any measuring instruments. To measure theLivelihood vulnerability, indicators under each dimension were selected after preliminary survey of the study area, consultation of the literature as well as the experts such as scientists, forest guard, forest conservator, officials of the related departments and personnel from NGOs working in the area. Due care was taken to include all relevant items. The procedure involved could ensure the efficiency of the instrument to measure the livelihood vulnerability by ascertaining content validity. Keeping in view the context of study, following proposed indicators under biophysical, social and institutional vulnerability were tested and the following steps were followed for selecting relevant indicators under each dimension of LVI:

Collection and editing of indicators: By referring the available literature on relevant subject, consultation of the researchers, farmers and extension experts, a total of 76 items (indicators) were collected covering the almost entire universe or content. The indicators were edited as per the 14 informal criteria suggested by Edwards (1957) and as an outcome 10 indicators were eliminated. Finally, 66 indicators were retained after editing and considered for judges' rating.

Judges' Rating: Selected indicators were subjected to the judges rating on 3 point continuum i.e. most relevant, relevant and not relevant with respective scores of 3,2 and 1 . The questionnaire containing 76 indicators on a three point continuums were sent by post, through Google forms, through e-mail and also handed over personally to the total 55 judges. These judges were experts in the field of forestry, wildlife, wildlife conservation, extension education, social science and rural development, etc. Out of 55 judges 40 judges had returned the same set of indicators after duly recording their judgments in a stipulated span of two month. Out of 40 responses, 9 responses were found unsuitable for item analysis and eliminated after careful examination of responses. The remaining 31 responses were considered for the item analysis.

Relevancy Test: These indicators were subjected to scrutiny and their subsequent screening for inclusion in the final index. The judges were asked to indicate degree of relevancy on each indicator in three point continuums 'Most Relevant, Relevant and Not Relevant' with respective scores of 3,2 and 1. The relevancy weightage (RW) and mean relevancy score (MRS) were worked out for all the selected indicators individually as well as overall mean relevancy score (OMRS) including all the indicators was calculated by using the following formula:

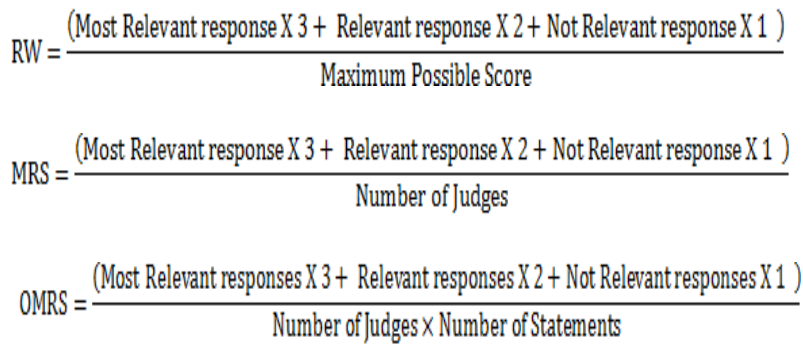

By these two criteria the statements having relevancy weightage $(\mathrm{RW})>0.85$ and Mean Relevancy Score (MRS) greater than the Overall Mean Relevancy Score i.e., 2.60 were considered for inclusion in Livelihood Vulnerability Index (LVI) and finally 46 indicators were included. The finally selected dimensions of Livelihood Vulnerability Index (LVI) and statements under these with 
respective relevancy weightage as well as mean relevancy scores are given in Table 2.

Construction of the composite Livelihood Vulnerability Index (LVI).

The first step is to construct the index (Iij) for each $\mathrm{i}^{\text {th }}$ indicator representing $\mathrm{j}^{\text {th }}$ dimension of composite sustainability index. For making indicator scale free following methods was applied:

$$
\begin{aligned}
I_{i j} & =\frac{\mathrm{Xij}_{\mathrm{ij}}-\mathrm{MinXij}}{\operatorname{MaxXij-MinXij~}}(1) \\
I_{i j} & =\frac{\mathrm{MaxXij}_{\mathrm{Xij}}}{\operatorname{Max} \mathrm{Xij}_{\mathrm{j}}-\mathrm{MinXij}}(2)
\end{aligned}
$$

Where

$\mathrm{i}=1,2,3 \ldots \ldots . \mathrm{n}$ Indicators

$\mathrm{j}=1,2,3$ Dimension of vulnerability

$\mathrm{X}_{\mathrm{ij}}=$ Value of $\mathrm{i}^{\text {th }}$ indicator of $\mathrm{j}^{\text {th }}$ dimension

Equation (1) will be applied for indicators having positive implication on vulnerability.

Equation (2) will be applied for indicators having negative implication on vulnerability.

Having calculated the $I_{\mathrm{ij}}$ for all the indicators, the second step is to calculate the indices for various dimensions of composite vulnerability index. It is calculated as the simple mean of their respective variables, that is:

BSI $=\frac{\sum_{i=1}^{n} I_{i j}}{n}, S S I=\frac{\sum_{i=1}^{n} I i j}{n}$ and $I S I=\frac{\sum_{i=1}^{n} I i j}{n}$

Whereas,

BSI= Biophysical Vulnerability Index

SSI=Social Vulnerability Index

ISI=Institutional Vulnerability Index

Iij= Index for the jth dimension containing $n$ indicator

$\mathrm{n}=$ No. of indicators
Then, the composite livestock owners livelihood vulnerability index for each respondent will be calculated as a weighted mean of the indices obtained for different dimensions of the Vulnerability in following manner:

\section{$\mathrm{W} 1 * \mathrm{BSI}+\mathrm{W} 2 * \mathrm{SSI}+\mathrm{W} 3 * \mathrm{ISI}$}

$\mathrm{LVI}=$

Sum of the scale values of all dimensions

Whereas,

$\mathrm{W}=$ Scale value (weight) assigned to the respective dimension of composite vulnerability index. (Chand and Sirohi, 2013)

Standardization of Index

The validity of the instrument was assessed by content validity. The content of the index was thoroughly covered with literature scan and expert opinions.

The indicators having relevancy score of $>0.85$ were retained. As it indicates that more than 85 per cent of judges rated the statement as relevant which indicates that statement is unambiguous. This indicated validity of the index content. As the scale values, relevancy weightages and mean relevancy scores of all the dimensions and indicators had discriminating values, it seemed reasonable to accept the index as valid measure of the desired dimension. Final Livelihood Vulnerability Index (LVI) and administration of it

The final index consisting of 46 (Table 2) indicators arranged under three dimensions of the vulnerability can be administered to respondents to measure the livelihood vulnerability since the index is scale free, the overall possible maximum and minimum score of vulnerability ranges between 1 to 0 . The score approaching unity will indicate high level of vulnerability and vice-versa. 
Table.1 Frequencies of ranks, proportions $(p), \mathrm{C}$ values and $\mathrm{R}_{\mathrm{c}}$ values for Three dimensions of LVI

\begin{tabular}{|c|c|c|c|c|c|c|c|c|c|}
\hline \multirow[t]{2}{*}{ ri } & \multirow[t]{2}{*}{$\mathbf{R i}$} & \multicolumn{5}{|c|}{ Five Sub dimensions of Livelihood Vulnerability Index } & \multirow[t]{2}{*}{$\sum$} & \multirow[t]{2}{*}{ p } & \multirow[t]{2}{*}{ C } \\
\hline & & $\begin{array}{l}\text { Human } \\
\text { Assets }\end{array}$ & $\begin{array}{l}\text { Natural } \\
\text { Assets }\end{array}$ & $\begin{array}{l}\text { Social } \\
\text { Assets }\end{array}$ & $\begin{array}{l}\text { Financial } \\
\text { Assets }\end{array}$ & $\begin{array}{l}\text { Physical } \\
\text { Assets }\end{array}$ & & & \\
\hline 1 & 1 & 6 & 5 & 8 & 6 & 4 & 31 & 90.00 & 8 \\
\hline 2 & 2 & 7 & 5 & 7 & 4 & 8 & 31 & 70.00 & 7 \\
\hline 3 & 3 & 8 & 7 & 4 & 7 & 7 & 31 & 50.00 & 6 \\
\hline 4 & 4 & 3 & 4 & 7 & 5 & 6 & 31 & 30.00 & 6 \\
\hline 5 & 5 & 7 & 10 & 5 & 9 & 6 & 31 & 10.00 & 5 \\
\hline$\sum \mathbf{f}$ & & 31 & 31 & 31 & 31 & 31 & 155 & 250 & 32 \\
\hline$\sum \mathbf{f C}$ & & 198 & 191 & 204 & 193 & 196 & 982 & & \\
\hline $\begin{array}{l}\text { Mc or } \\
\text { Rj or } \\
\text { Rc }\end{array}$ & & 6.39 & 6.16 & 6.58 & 6.23 & 6.32 & 31.68 & $\begin{array}{c}\mathrm{M}= \\
\sigma=0 \\
\text { Stan } \\
\text { error } \\
\mathrm{Mc}=\end{array}$ & \\
\hline $\begin{array}{l}i=\text { Co } \\
\text { espect } \\
\text { eviati }\end{array}$ & & $\begin{array}{l}\text { order } \\
\mathrm{Mc}= \\
\text { ard Er }\end{array}$ & $=\mathbf{R e}$ & al & $\begin{array}{l}\text { der, } \sum= \\
\text { onse va } \\
15 / 5.57=\end{array}$ & $p=\operatorname{Pr}$ & & $=\mathbf{C}$ va & es o \\
\hline
\end{tabular}

Table.2 A list of selected indicators with Mean Relevancy Weightage (MRW), Mean Relevancy Score (MRS) for construction of Livelihood Vulnerability index

\begin{tabular}{|c|c|c|c|c|}
\hline Dimensions & Indicators & Sub-Indicators & R weightage & MRS \\
\hline \multirow{18}{*}{ 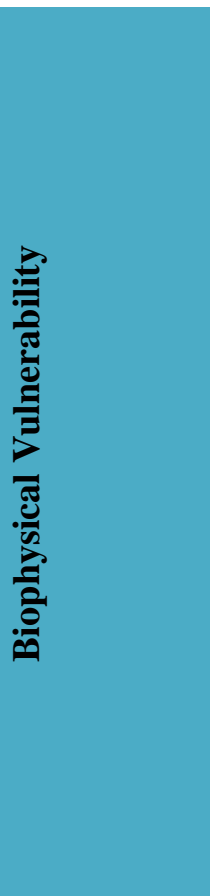 } & \multirow{8}{*}{$\begin{array}{c}\text { Human } \\
\text { Assets }\end{array}$} & Age of head of household & 0.90 & 2.71 \\
\hline & & Diverse conflict mitigation skill & 0.89 & 2.68 \\
\hline & & Awareness regarding conflict mitigation & 0.87 & 2.61 \\
\hline & & Traditional knowledge & 0.91 & 2.74 \\
\hline & & Training received & 0.80 & 2.39 \\
\hline & & Working manpower in family & 0.76 & 2.29 \\
\hline & & Hired man force & 0.88 & 2.65 \\
\hline & & Injury to human by wild animals & 0.78 & 2.35 \\
\hline & \multirow{10}{*}{$\begin{array}{c}\text { Natural } \\
\text { Assets }\end{array}$} & Crop cultivated area & 0.84 & 2.52 \\
\hline & & Land holding & 0.80 & 2.39 \\
\hline & & Crop yield & 0.87 & 2.61 \\
\hline & & Herd size & 0.86 & 2.58 \\
\hline & & $\begin{array}{l}\text { Percent of households that utilize natural water } \\
\text { source }\end{array}$ & 0.77 & 2.32 \\
\hline & & Crop diversification & 0.88 & 2.65 \\
\hline & & Water availability for crop & 0.89 & 2.68 \\
\hline & & Average ground water level & 0.76 & 2.29 \\
\hline & & Farm diversification & 0.91 & 2.74 \\
\hline & & Natural hazards & 0.88 & 2.65 \\
\hline
\end{tabular}




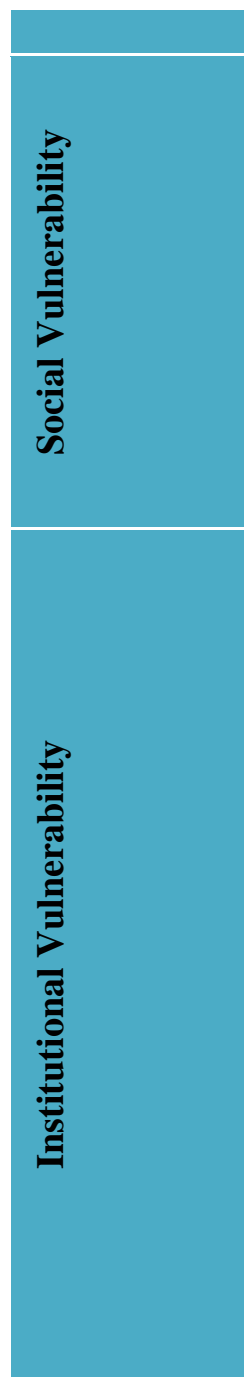

\begin{tabular}{|c|c|c|c|}
\hline & Firewood & 0.87 & 2.61 \\
\hline \multirow{10}{*}{$\begin{array}{l}\text { Social } \\
\text { Assets }\end{array}$} & Family size & 0.80 & 2.39 \\
\hline & Membership of SHGs & 0.77 & 2.32 \\
\hline & Legal penalties by Government & 0.81 & 2.42 \\
\hline & Culture and taboo & 0.85 & 2.55 \\
\hline & Social migration due to conflict & 0.86 & 2.58 \\
\hline & Membership of Cooperatives & 0.77 & 2.32 \\
\hline & Forest rules and regulation & 0.87 & 2.61 \\
\hline & Role of social leader in conflict management & 0.82 & 2.45 \\
\hline & Socio-political participation & 0.86 & 2.58 \\
\hline & Festivals and religious activity & 0.77 & 2.32 \\
\hline \multirow{11}{*}{$\begin{array}{l}\text { Financial } \\
\text { Assets }\end{array}$} & Saving form Agricultural activity & 0.81 & 2.42 \\
\hline & Average Family Income & 0.85 & 2.55 \\
\hline & Occupation & 0.84 & 2.52 \\
\hline & Off-farm employment opportunities & 0.86 & 2.58 \\
\hline & Crop loss due to wild animals (Area) & 0.89 & 2.68 \\
\hline & Crop loss due to wild animals (In Rupees) & 0.94 & 2.81 \\
\hline & Remittances & 0.88 & 2.65 \\
\hline & Compensation for loss/ damage & 0.89 & 2.68 \\
\hline & Government supported mitigation & 0.86 & 2.58 \\
\hline & Percent of household access credit facilities & 0.83 & 2.48 \\
\hline & Major source of family income & 0.88 & 2.65 \\
\hline \multirow{6}{*}{$\begin{array}{c}\text { Physical } \\
\text { Assets }\end{array}$} & Livestock & 0.91 & 2.74 \\
\hline & $\begin{array}{l}\text { Household that experience damage to } \\
\text { infrastructure }\end{array}$ & 0.90 & 2.71 \\
\hline & Shelter & 0.87 & 2.61 \\
\hline & Access to information & 0.83 & 2.61 \\
\hline & Tools and equipment in farming & 0.83 & 2.48 \\
\hline & Food loss or shortage causes hunger & 0.89 & 2.68 \\
\hline
\end{tabular}

Table.3 Distribution of respondents according to Livelihood Vulnerability index

$(n=50)$

\begin{tabular}{|c|c|c|c|c|}
\hline Sl. No. & Variables & Category & Frequency & Percentage \\
\hline \multirow[t]{3}{*}{1.} & \multirow{3}{*}{$\begin{array}{l}\text { Biophysical Vulnerability } \\
\quad \text { (Index Value }=0.30)\end{array}$} & Low $(<0.23)$ & 11 & 22.00 \\
\hline & & Medium (0.23-0.73) & 31 & 62.00 \\
\hline & & $\operatorname{High}(>0.73)$ & 8 & 16.00 \\
\hline \multirow[t]{3}{*}{2.} & \multirow{3}{*}{$\begin{array}{l}\text { Social Vulnerability } \\
\text { (Index Value }=0.39 \text { ) }\end{array}$} & Low $(<0.16)$ & 12 & 24.00 \\
\hline & & Medium (0.16-0.63) & 31 & 62.00 \\
\hline & & $\operatorname{High}(>0.63)$ & 7 & 14.00 \\
\hline \multirow[t]{3}{*}{3.} & \multirow{3}{*}{$\begin{array}{l}\text { Institutional Vulnerability } \\
\quad(\text { Index value }=0.29)\end{array}$} & Low $(<0.27)$ & 9 & 18.00 \\
\hline & & Medium (0.78-0.72) & 29 & 58.00 \\
\hline & & $\operatorname{High}(>0.72)$ & 12 & 24.00 \\
\hline \multirow[t]{3}{*}{4.} & \multirow{3}{*}{$\begin{array}{c}\text { Overall Vulnerability } \\
\text { (Mean Index Value }=0.33 \text { ) }\end{array}$} & Low $(<0.28)$ & 7 & 14.00 \\
\hline & & Medium (0.29-0.73) & 32 & 64.00 \\
\hline & & $\operatorname{High}(>0.73)$ & 11 & 22.00 \\
\hline
\end{tabular}




\section{Results and Discussion}

The final set of the 46 statements which represent the livelihood vulnerability, was administered on form of interview schedule to a fresh group of 50 farmers, which were not included in the actual sample. It was observed that the average indices for biophysical, social and institutional vulnerability and overall livelihood vulnerability were found to be $6.28,6.58$, and6.27 respectively. In majority of cases, the overall as well as different aspects vulnerability was found to be the medium (Table 3).

Vulnerability is conceptualized in diverse ways by academics from different knowledge domains, and even within the same domain. Validity of the index indicates the precision and consistency of the results. Though methods of vulnerability assessment have been developed over the past several decades in natural hazards, food security, poverty analysis, sustainable livelihoods and related fields. Livelihoods are the mechanisms through which livestock owners translate natural resources into the things they need to survive, thrive and mitigate. Information on vulnerabilities aspect of livestock farming would be a priceless resource to policy makers for designing policies in order to reduce vulnerabilities of the sector as well as farmers. This index can be used to measure the vulnerabilities of livestock rearing beyond the study area with suitable modifications and evaluation of reliability and validity.

\section{Acknowledgement}

Authors acknowledge the financial support given by UGC and ICAR-National Dairy Research Institute to carry out the Ph.D. work and Dr. B.S. Meena and Dr. Gopal Sankhala, of Dairy Extension Division, NDRI for his valuable inputs.

\section{References}

Adger, W. N. and Kelly, P. M. 1999. 'Social Vulnerability to Climate Change and the Architecture of Entitlements', Mitigation Adaptation Strategies Global Change 4, 253-256.

Anonymous. 2013. National Livestock Policy. Department of Animal Husbandry, Dairying and Fisheries, Ministry of Agriculture, Government of India, New Delhi, pp.1-28

Barua, M., Bhagwat, S. A., and Jadhav, S. 2013. The hidden dimensions of human- wildlife conflict: health impacts, opportunity and transaction costs. Biological Conservation, 157, 309-316.

Chand P, Sirohi S (2013) Sustainability of dairy breeding practices: Empirical evidences of semi-arid eastern zone of Rajasthan, Res. J. Animal Hus. and Dairy Sci. 4(2): 47-50.

Dale, V.H., Beyeler, S.C. 2001. Challenges in the development and use of ecological indicators. Ecological Indicators, 1(1): 3-10.

Edwards A.L. 1957. Techniques of Attitude Scale Construction. Vakils, Feffer and Simons Private Ltd., Bombay.

Eniang E. A., Ijeomah H.M., Okeyoyin G. and Uwatt A.E. 2011. Production Agriculture and Technology Journal, 1, 15-35.

Guilford J.P. 1954 Psychometric Methods (2 ${ }^{\text {nd }}$ ed.). McGraw-Hill, New York, pp 1597

Hardaker, J.B., Huirne, R.B.M, Anderson, J.R., Lien, G. 2004. Coping with risk in agriculture, Second edition, $\mathrm{CABi}$ Publishing, London, UK.

Kepe, T., M. Saruchera, and W. Whande. 2004. Poverty alleviation and biodiversity conservation: A South African perspective. Oryx 38: 143-145. 
Kerlinger F.N. 2012. Foundations of Behavioral Research (Second ed.). Fourteenth reprint, 2012. Surjeet Pub., Delhi, India, pp1-741.

Kumar Mukesh, Meena H.R. and Paul Pampi. 2016. Livestock Owners' Perception towards Wildlife Conflict: A methodological Approach. International Journal of Agriculture Sciences, 8(51): 2256-2259.

Letha Devi G, Dhirendra Varma, Mukund A Kataktalware. 2016. The Livelihood Vulnerability Analysis: A Pragmatic Approach to Assessing Risks from Climate Variability and Change-a Case Study of Livestock Farming In Karnataka, India. Journal of Agriculture and Veterinary Science, 9(2): 15-19.

Maikhuri, R. K., Nautiyal, S., Rao, K. S., and Saxena, K. $\quad$ G. 2001. Conservationpolicy-people conflicts: a case study from Nanda Devi Biosphere Reserve (aworld heritage site), India. Forest Policy and Economics, 2(3), 355-365.

Nepal, S. K., and Weber, K. E. 1995. Prospects for coexistence: wildlife and localpeople. Ambio, 238-245.

Polisar, J., I. Maxit, D. Scognamillo, L. Farrell, M.E. Sunquist, and J.F. Eisenberg. 2003. Jaguars, pumas, their prey base, and cattle ranching: Ecological interpretations of a management problem. Biological Conservation 109: 297-310.

Rode, K. D., Chiyo, P. I., Chapman, C. A., and McDowell, L. R. 2006. Nutritional ecology of elephants in Kibale National Park, Uganda, and its relationship with crop-raiding behaviour. Journal of tropical ecology, 22(4), 441-449.

Treves A., Wallace R.B., Naughton-Treves L. and Morales A. 2006. Human Dimensions of Wildlife, 11, 383-396.

Tshering and Thinley. 2017. Assessing livestock herding practices of agropastoralists in western Bhutan: Livestock vulnerability to predation and implications for livestock management policy. Pastoralism: Research, Policy and Practice 7: 5. DOI 10.1186/s13570017-0077-1.

Wang, S. W., and Macdonald, D. W. 2006. Livestock predation by carnivores in Jigme Singye Wangchuck National Park, Bhutan. Biological Conservation, 129(4), 558-565.

Wang, S. W., Lassoie, J. P., and Curtis, P. D. 2006. Farmer attitudes towards conservation in Jigme Singye Wangchuck National Park, Bhutan. Environmental Conservation, 33(2), 148-156.

Wisner, B., Blaikie, P., Cannon, T., and Davis, I. 2004. At Risk: natural hazards, people's vulnerability and disasters, London, Routledge.

World Bank 1999. India Livestock Sector Review: Enhancing Growth and Development. The World Bank, Washington D.C. and Allied Publishers, New Delhi.

\section{How to cite this article:}

Mukesh Kumar, H.R. Meena, Pankaj Seth and Niva Bara. 2018. An Index to Measure Vulnerability of Livestock Owners Livelihood in the Vicinity of National Park. Int.J.Curr.Microbiol.App.Sci. 7(08): 2889-2898. doi: https://doi.org/10.20546/ijcmas.2018.708.306 